364

\section{BODY COMPOSITION IN SMALL FOR GESTATIONAL AND LARGE FOR GESTATIONAL AGE INFANTS AT ONE WEEK AND 12 WEEKS OF AGE}

\author{
E. Olhager ${ }^{1}$, C. Törnqvist ${ }^{2}$, I. Danielsson ${ }^{2}$
}

${ }^{1}$ Division of Paediatrics, Department of Clinical and Experimental Medicine, Faculty of Health Science,

${ }^{2}$ Division of Paediatrics, Department of Clinical and Experimental Medicine, University Hospital, Linköping, Sweden

Background: Full term infants born small for gestational age (SGA) or large for gestational age (LGA) are at an increased risk for metabolic complication. Improved nutrition with catch-up growth has been related to insulin resistant and metabolic syndrome leading to the concern that "bigger might not be better".

Aims: To use Pea Pad, a device based on air displacement plethysomgraphy, to compare body composition in full-term infants born SGA and LGA.

Methods: Body composition was assessed in 20 infants born SGA and in 20 infants born LGA in the first week of life and at 12 weeks.

Results: At one week SGA infants contained 3,9 $( \pm 2,0) \%$ body fat and LGA infants contained 16,3 $( \pm 5,2) \%$ body fat. At 12 weeks SGA infants body weight were 6071 ( \pm 675$) \mathrm{g}$ and contained 26 ( \pm $4,1) \%$ body fat. LGA infants body weight were 7205 $( \pm 792) \mathrm{g}$ and contained $27,3( \pm 5,0) \%$ body fat. There was a significant difference in body weight, but no significant difference in \% body fat $(p=0,59)$ between the groups at 12 weeks. The regression line between body fat (dependent variable) and body weight was for SGA infants at 12 weeks $y=4,46+$ $0,04 x, r=0,58, p=0,003$ and for LGA infants $y=20,9$ $+0,001 x, r=0,14, p=0,6$

Conclusions: The catch up growth in SGA infants consist of "catch up fat" compared to LGA infants. It seems that LGA infants sustained a metabolic capacity and SGA developed a metabolic load at 12 weeks.

\section{GROWTH OF EXTREMELY LOW BIRTH WEIGHT INFANTS DURING TWO DECADES}

\author{
P. Luukkainen'1, E. Huttunen², S. Andersson ${ }^{1}$
}

${ }^{1}$ Neonatal Intensive Care Unit, Helsinki University Hospital, ${ }^{2}$ University of Helsinki, Helsinki, Finland

Postnatal growth retardation is common among ELBW infants and poor head circumference (HC) growth has been associated with poor cognitive outcome. We studied whether postnatal growth of ELBW infants has improved during the last decade.

Subjects and methods: ELBW infants admitted to the NICU of the Helsinki University Hospital during yr 1996-7 ( $n=61)$ and 2006-7 $(n=64)$ with follow up data available up to 12 mo of co age were included. Growth parameters were collected retrospectively, Student's t-test used for statistical analyses and $p<$ 0.05 considered significant.

Results: The mean gestational age, weight, length and $\mathrm{HC}$ at birth were similar in both periods. Boys born during the latter period were heavier, longer and had a larger HC at 40 wk (3292 vs $2684 \mathrm{~g}, 49.0$ vs $46.6 \mathrm{~cm}$ and 36.0 vs $33.9 \mathrm{~cm}, \mathrm{p}<0.05)$ and at 12 mo co age (9607 vs $8962 \mathrm{~g}, 76.4$ vs $74.3 \mathrm{~cm}$ and 47.5 vs $46.1 \mathrm{~cm}, p<0.05)$ than those born during the first period. Girls born during the latter period were longer ( $74.1 \mathrm{vs} 72.0 \mathrm{~cm}, \mathrm{p}<0.05$ ) and had a larger $\mathrm{HC}$ (45.9 vs $44.7 \mathrm{~cm}, \mathrm{p}<0.05)$ at 12 mo than those born during the first period. The daily weight gain before 40wk of gestation tended to be higher during the latter period ( $23.4 \mathrm{~g}$ vs $20.8 \mathrm{~g}, \mathrm{p}=0.06$ ).

Conclusion: ELBW infants born 2006-7 had a larger $\mathrm{HC}$ and were longer at 12 mo corrected age than those born 1996-7. 